\title{
A comparative study of metformin and glyburide in gestational diabetes mellitus
}

\author{
Prashant Pujara $^{1 *}$, Vinita Singh ${ }^{1}$, Sunita Murmu ${ }^{1}$, Suman Kumari ${ }^{1}$, Dhara Prajapati ${ }^{2}$
}

${ }^{1}$ Department of Obstetrics and Gynecology, Tata Main Hospital, Jharkhand, India

${ }^{2}$ Department of Preventive and Social Medicine, GMERS Medical College, Gujarat, India

Received: 01 February 2017

Revised: 13 February 2017

Accepted: 03 March 2017

\section{*Correspondence:}

Dr. Prashant Pujara,

E-mail: drprashantpujara@gmail.com

Copyright: ( $)$ the author(s), publisher and licensee Medip Academy. This is an open-access article distributed under the terms of the Creative Commons Attribution Non-Commercial License, which permits unrestricted non-commercial use, distribution, and reproduction in any medium, provided the original work is properly cited.

\begin{abstract}
Background: Incidence of gestational diabetes mellitus (GDM) is increasing worldwide. GDM provides a window of opportunity for the primary prevention of the type 2 diabetes by preventing transgeneration transmission to fetus. Insulin in management of GDM has many drawbacks, so use of OHAs has been increased worldwide.

Methods: Randomized control trial was performed in patients with GDM who required medical management. Subjects were randomized into two groups and treated with Metformin and Glyburide, results were compared.

Results: While comparing efficacy of metformin and glyburide in this study for maternal variables; the failure rate of metformin was found to be 9.39 times higher compared to glyburide. Glyburide was associated with 9.5 times more risk to develop hypoglycemia in mother compared to metformin. While comparing neonatal variables nursery admission was found to be more and statistically significant in neonates whose mother has received glyburide compared to metformin $(\mathrm{p}=0.03, \mathrm{RR}=2.26)$. Though statistically insignificant, LGA fetuses and neonatal hypoglycemia were 2.1 times more in glyburide group compared to metformin.

Conclusions: Though glyburide can be effective alternative to metformin and insulin for GDM, it is associated with higher risk of maternal hypoglycemia, neonatal hypoglycemia, LGA fetuses and higher rate of nursery admissions compared to metformin. Higher adverse neonatal outcomes with glyburide use question the widespread use of glyburide as first line management modality in GDM and also as an alternative to insulin as advised by many groups.
\end{abstract}

Keywords: Diabetes in pregnancy, Gestational diabetes, Glyburide, Metformin, Oral hypoglycemic drugs

\section{INTRODUCTION}

Gestational diabetes mellitus (GDM) is defined by the World Health Organization (WHO) and the Diabetes in Pregnancy Study Group India (DIPSI) as any degree of glucose/carbohydrate intolerance with onset or first recognition during pregnancy. ${ }^{1-3}$ Worldwide, one in six pregnancies may be associated with hyperglycemia, majority $(\sim 84 \%)$ of which involve GDM with the remainder divided between pregestational type 1 diabetes and type 2 diabetes. In South-East Asia, one in four live births may occur in the setting of maternal hyperglycemia during pregnancy. The global prevalence of hyperglycemia in pregnant women (20-49 years) is $16.9 \%$ or 21.4 million live births in $2013 .^{2,4}$ By WHO criteria of $2 \mathrm{hr}$. plasma glucose $\geq 140 \mathrm{mg} / \mathrm{dl}$ the prevalence of GDM in India was $16.55 \%$ in $2004 .^{5}$

According to DIPSI a single step screening and diagnostic testing should be performed in all pregnant women at 16 weeks of pregnancy and followed up with a second screening test between 24-26 weeks of pregnancy and third after 30 weeks (32-34 weeks) of pregnancy with a standard oral glucose tolerance test (OGTT), irrespective of meals, by giving $75 \mathrm{~g}$ anhydrous glucose. Plasma glucose should be measured after 2 hours. ${ }^{6}$ 
Medical nutrition therapy (MNT) and daily selfmonitoring of blood glucose (SMBG) concentrations are cornerstones in the treatment of GDM. ${ }^{7,8}$ However approximately $30 \%$ patients fail to achieve the desired levels of glycemic control and require pharmacological intervention. ${ }^{9}$ Historically, insulin therapy has been the first line pharmacological treatment in GDM, but recently oral agents, especially metformin and glyburide, have been under investigation. ${ }^{10}$ The need of searching scope of oral hypoglycemic agents in management of gestational diabetes is because insulin treatment is expensive, needs frequent monitoring, requires refrigerated storage, skilled handling, is to be taken in divided doses and therefore may not be popular with poor and illiterate women in low resource countries. Good patient compliance to treatment with these hypoglycemic agents, as well as their low-cost, calls for their increased use in low resource countries.

Use of oral agents is increasing, and in many settings they are the first option when pharmacological treatment is required for women with GDM. ${ }^{11,12}$ In a large nationwide retrospective cohort study in the United States including 10,778 women with drug treated gestational diabetes, use of glibenclamide (glyburide) increased from $7.4 \%$ in 2000 to $64.5 \%$ in 2011 , superseding insulin as most common treatment since $2007 .{ }^{11}$ In spite of all these studies answer of the question which oral hypoglycaemic should be used for gestational diabetes? needs more work to do on both agents. ${ }^{13}$

The number of GDM patients treated with glyburide is still low in India. Till now, in India onlythree trials have compared glyburide and insulin. ${ }^{14-16}$ Worldwide only two trials compared metformin and glyburide head tohead. Studies were performed in the Mexico and Brazil, and diagnostic criteria were those of Carpenter and Coustan and the WHO respectively. ${ }^{17,18}$

We undertook this study in order to determine the effects of glyburide and metformin in the Indian pregnant womendiagnosed to have gestational diabetes mellitus according to DIPSI criteria and to compare each other. ${ }^{2}$

\section{METHODS}

The study was carried out in the Obstetrics and Gynaecology Department of Tata Main Hospital, Jamshedpur with an aim to assess maternal glycemic control in GDM when treated with Glyburide and Metformin during antenatal period and objectives to compare the efficacy of Glyburide and Metformin in controlling glucose levels, assess the obstetric, fetal and neonatal complications in GDM treated with Glyburide and Metformin. This prospective randomized comparative interventional study was performed over a period of one year from $15^{\text {th }}$ September 2014 to $15^{\text {th }}$ September 2015. Patients who were diagnosed with GDM according to DIPSI guidelines were randomized into two groups if they are not able to achieve glycemic targets after medical nutrition therapy and exercise.

It was approved by the Research Ethics Committee of the Tata Main Hospital on $7^{\text {th }}$ September 2014.

\section{Inclusion criteria}

- $\quad$ Age 18 to 40 years

- Singleton pregnancy

- Gestational age 10 weeks to 34 weeks

\section{Exclusion criteria}

- Multiple pregnancy

- Patient seen for first time after 34 weeks and not treated for diabetes

- Patients in whom the interval between starting an anti-diabetic drug and delivery is less than 2 weeks

- Patient who were lost to follow up

- Patient who were not able to achieve glycemic targets on oral hypoglycaemic agents and required replacement with or addition of insulin (they were included in deciding efficacy)

- Maternal intolerance to the hypoglycaemic medications

- Unwillingness to participate

- Foetal risk (abdominal circumference $>97 \%$ or $<5 \%$ of normal)

- Presence of fetal anomalies identified by ultrasonography prior to initiation of treatment

- Allergy to sulfa drugs

- Known case of diabetes mellitus

- Known case of PCOS receiving oral hypoglycaemic drugs

- Pregnancies after IUI or IVF

- $\quad$ Smoking

As shown in Figure 1, women attending antenatal clinic were screened for GDM with 2-h 75-g oral glucose tolerance test at the first antenatal visit or at 11-16 weeks. If initial screening was negative, the test was repeated between 24-28 weeks and again in between 32-34 week. At any time patients with plasma glucose of $\geq 140 \mathrm{mg} / \mathrm{dL}$ were diagnosed as having gestational diabetes mellitus.

Once diagnosis was made, MNT along with exercise was advised initially for 2 weeks. If GDM was diagnosed after 30 weeks; MNT with exercise was advised for a week. After initiating medical nutrition therapy and exercise, the participants self-assessed their glucose level upon awakening, and then 2 hour after breakfast, lunch, and dinner using a home capillary glucose monitoring device. Acceptable upper values were fasting level of 90 $\mathrm{mg} / \mathrm{dL}$ and a postprandial level of $120 \mathrm{mg} / \mathrm{dL}$. Those who were controlled on diet were excluded from the study. The women were offered participation in the study if 2 readings were abnormal on the first day of self assessment at the end of MNT and exercise. 
When selected, their fasting and postprandial glucose levels were monitored twice weekly throughout the study to adjust the dosage of the medication. The participants were randomised to the glyburide or metformin group, using a random number table. Written informed consent was taken from every patient before enrolment.

In the glyburide group, the participants first took $2.5 \mathrm{mg}$ of the medication prior to breakfast and dinner twice daily and increased the dosage by 2.5 to $5 \mathrm{mg}$ each week until glucose control was achieved, or to a maximum daily dose of $20 \mathrm{mg}$.

In the metformin group, the participants first took $500 \mathrm{mg}$ of the medication in divided doses and increased the dosage by 500 to $1000 \mathrm{mg}$ each week until glucose control was achieved, or to a maximum daily dose of $2500 \mathrm{mg}$.

Medication dose was increased if two or more glucose levels in the same meal exceeded target values by 10 $\mathrm{mg} / \mathrm{dL}$ or greater for 1 week. Patients taking the maximum dose of either metformin or glyburide with two or more glucose values in the same meal exceeding target glucose values by $10 \mathrm{mg} / \mathrm{dL}$ or greater for 1 consecutive week were considered treatment failures. Patients with failed metformin treatment were treated with maximum dose of metformin with insulin and with failed glyburide treatment were treated with insulin after stopping glyburide completely. 13 maternal and 9 fetal variables were compared in between both groups. The maternal variables which were used for analysis were.

- Age,

- Number of previous pregnancies (parity),

- Family history of diabetes,

- Past history of GDM,

- Value of 75-gm 2 hour OGTT value,

- Body mass index (calculated as weight in kilograms divided by height in meters squared) at diagnosis of GDM,

- Glycated hemoglobin (A1C) at diagnosis of GDM,

- Gestational age at diagnosis of GDM (weeks),

- Gestational age at the time of inclusion in the study (estimated by the first ultrasound scan),

- Weeks of treatment with oral hypoglycaemic agents,

- Development of hypertensive disorders of pregnancy (blood pressure $\geq 140 / 90 \mathrm{mmHg}$ ) and maternal hypoglycemia $(<60 \quad \mathrm{mg} / \mathrm{dL})$ during antenatal period

- $\quad$ Sugar levels (fasting, 2 hour post breakfast, 2 hour post lunch, 2 hour post dinner) during antenatal period,

- Who fail to achieve glycemic target on oral hypoglycaemic agent.
The fetal and neonatal variables which were used for analysis were:

- Gestational age at delivery (weeks),

- Mode of delivery,

- Weight of baby,

- The number of large-for-gestational-age newborns (LGA) and small-for-gestational-age newborns (SGA) using fenton's growth chart) (weight is $>90 \%$ percentile in growth curves),

- Intrauterine fetal demise,

- Intrapartum complications,

- Presence of neonatal hypoglycemia ( $<40 \mathrm{mg} / \mathrm{dL})$,

- Capillary glucose test results in the first, second, and fourth hour after delivery,

- Nursery admissions.

\section{Statistical analysis}

Student t test (two tailed, independent) has been used to find the significance of study parameters on continuous scale between two groups (inter group analysis) on metric parameters. Chi-square/Fisher Exact test has been used to find the significance of study parameters on categorical scale between two or more groups. Relative risk was calculated when both drugs were compared for any particular outcome.

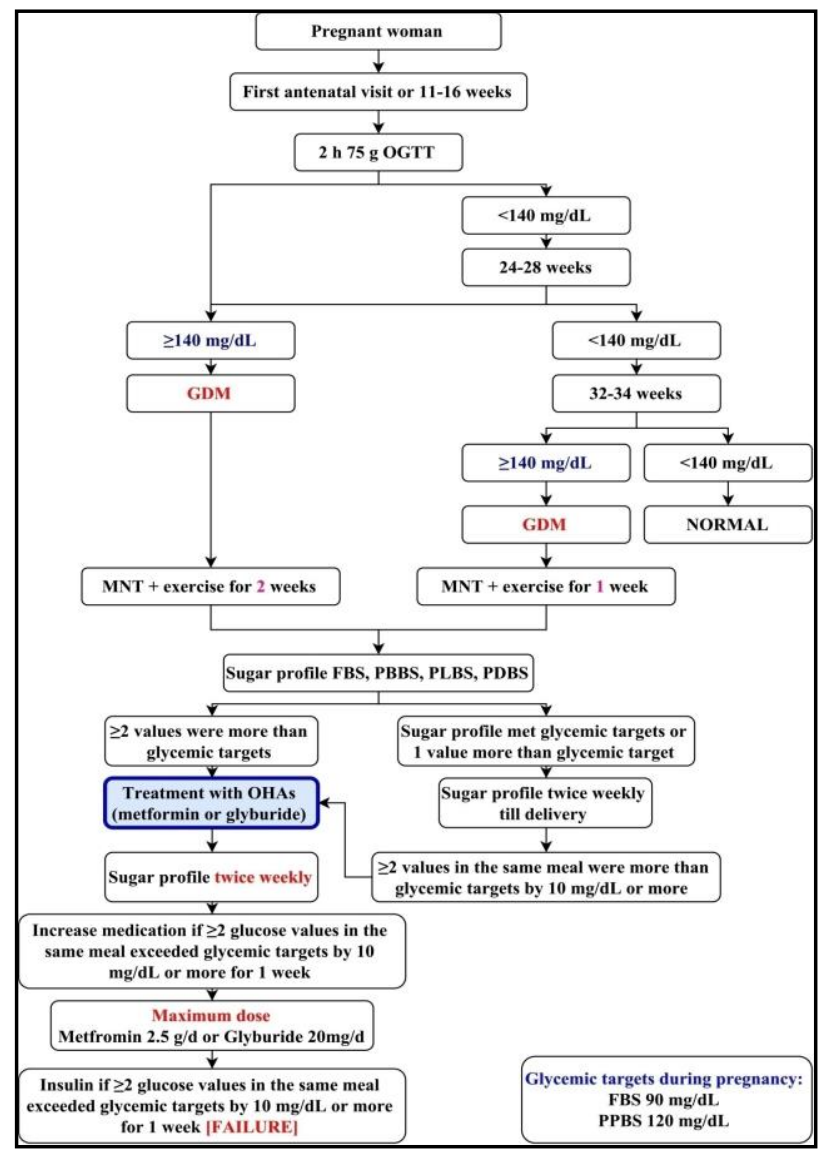

Figure 1: Women attending antenatal clinic for GDM. 


\section{RESULTS}

As shown in Figure 2 when above described methodology was applied, 188 women were diagnosed to have GDM. Out of them $97(51.6 \%)$ patients were treated with MNT and exercise. Remaining 91 (48.4\%) patients were not able to achieve glycemic targets with MNT and exercise and required oral hypoglycemic agents.



Figure 2: Women diagnosed to have GDM.

Out of 97 patients treated with MNT and exercise 3 were lost to follow up and 3 are on follow up with MNT who are not yet delivered. Remaining 91 (50\%) patients were managed with MNT and exercise till the end of delivery.

Out of 188 patients of GDM; MNT with exercise failed to achieve the glycemic targets in 91 (50\%) patients and they were started on OHA. Out of 91 patients treated with OHAs, 52 received metformin and 39 received glyburide. Out of 52 patients of metformin; 2 developed gastrointestinal intolerance and 13 required supplemental insulin. These 15 patients were excluded while comparing maternal and fetal variables.

Out of 39 patients of glyburide; 2 developed hypoglycemia who were subsequently managed on MNT, 1 lost to follow up and 1 required replacement with insulin. These 4 patients were excluded while comparing maternal and fetal variables. 13 maternal and 9 fetal variables were compared in between remaining 37 patients of metformin and 35 patients of glyburide. Efficacy of drug was compared in between 50 patients of metformin and 36 patients of glyburide.

\section{Maternal variables}

\section{Age distribution}

The mean age of patient in metformin and glyburide group was 29.59 years and 30.6 years respectively; the difference being statistically not significant $(\mathrm{p}=0.339)$. Majority of the patients belong to 30-35 years age group in both metformin (54.05\%) and glyburide (34.28\%) group.

\section{Number of previous pregnancies except miscarriage}

Majority of the GDM women in study were primigravida (nulliparous) in both metformin $(n=24,64.86 \%)$ and glyburide $(n=16,45.71 \%)$ group and difference between both group were not significant ( $\mathrm{p}$ value $=0.53$ ).

\section{History}

Family history of GDM was present in total 17 (23.61\%) patients out of 72 who received OHAs. Out of 72 women who received OHAs, 2 had past history of GDM. Table 1 shows that distribution of all these patients in both groups (metformin and glyburide) were statistically not significant $(\mathrm{p}=0.4103,1)$.

Table 1: Distribution of all these patients.

\begin{tabular}{llll} 
History & MIETFOR & GLYBURI & p \\
Fam $(\mathbf{n}=37)$ & DE $(\mathbf{n = 3 5})$ & value \\
$\begin{array}{l}\text { Family history of } \\
\text { diabetes }\end{array}$ & 7 & 10 & 0.41 \\
$\begin{array}{l}\text { Past history of } \\
\text { GDM }\end{array}$ & 1 & 1 & 1 \\
\hline
\end{tabular}

test used for calculating $\mathrm{p}$ value $=$ Fisher's exact test Value of $75 \mathrm{~g}$ 2-h OGTT at diagnosis of GDM

Table 2 shows the mean value of 2 -hr $75 \mathrm{~g}$ OGTT value in metformin and glyburide group as $164.19 \pm 15.69$ $\mathrm{mg} / \mathrm{dl}$ and $170.68 \pm 15.75 \mathrm{mg} / \mathrm{dl}$ respectively; the difference being statistically not significant $(\mathrm{p}=0.0843)$. Majority of the patients belong to $161-180 \mathrm{mg} / \mathrm{dl}$ group in both metformin and glyburide group. Comparison between frequency distribution is not done as number of sample is small.

Table 2: Value of $75 \mathrm{~g}$ 2-h OGTT at diagnosis of GDM.

\begin{tabular}{|lll|}
\hline $\begin{array}{l}75 \text { gm 2-hr } \\
\text { OGTT }(\mathrm{mg} / \mathrm{dl})\end{array}$ & $\begin{array}{l}\text { Metformin } \\
(\mathrm{n}=37)\end{array}$ & $\begin{array}{l}\text { Glyburide } \\
(\mathrm{n}=35)\end{array}$ \\
\hline $140-160$ & 16 & 9 \\
\hline $161-180$ & 18 & 17 \\
\hline $181-200$ & 2 & 7 \\
\hline$>200$ & 1 & 2 \\
\hline Mean \pm SD & $164.19 \pm 15.69$ & $170.68 \pm 15.75$ \\
\hline p value = 0.0843 & \\
\hline \multicolumn{2}{l}{ Test used for calculating p value = Unpaired t test } \\
\hline
\end{tabular}

\section{Gestational age at diagnosis}

The mean gestational age in weeks at diagnosis of GDM in metformin and glyburide group as $24.85 \pm 6.45$ weeks and $22.39 \pm 7.49$ weeks respectively; the difference being statistically not significant $(\mathrm{p}=0.1392)$. It shows that majority of the patients were diagnosed as GDM before 
$280 / 7$ weeks in both metformin $(54.05 \%)$ and glyburide $(85.71 \%)$ group.

Gestational age in weeks at entry into study or beginning of oral hypoglycemic agent

The mean gestational age at entry or beginning of oral hypoglycemic agents in GDM women in metformin and glyburide group was $26.55 \pm 6.17$ weeks and24.59 \pm 7.3 weeks respectively; the difference being statistically not significant $(\mathrm{p}=0.2218)$. Majority of the patients have received oral hypoglycemic agents after $280 / 7$ weeks in both metformin (72.97\%) and glyburide (40\%) group.

\section{Weeks of treatment with oral hypoglycemic agent}

The mean weeks of treatment with oral hypoglycemic agents in GDM women in metformin and glyburide group

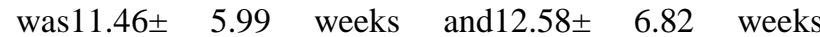
respectively; the difference being slightly statistically not significant $(p=0.46)$. Majority of the patients have received oral hypoglycemic agents for 2-10 weeks in both metformin $(75.67 \%)$ and glyburide $(45.71 \%)$ group.

\section{BMI at the diagnosis of GDM}

The mean value of BMI at the diagnosis of GDM in metformin and glyburide group was $29.08 \pm 9.89 \mathrm{~kg} / \mathrm{m} 2$ and $29.49 \pm 9.99 \mathrm{~kg} / \mathrm{m} 2$ respectively; the difference being statistically not significant $(\mathrm{p}=0.86)$. Majority of the patients belong to $25-29.99 \mathrm{~kg} / \mathrm{m} 2$ group in both metformin (62.16\%) and glyburide $(57.14 \%)$ group.

\section{$A 1 C$ at the diagnosis of GDM}

The mean value of $\mathrm{A} 1 \mathrm{C}$ at the diagnosis of GDM in metformin and glyburide group was $5.06 \pm 0.679 \%$ and $5.52 \pm 0.67 \%$ respectively; the difference being statistically not significant $(\mathrm{p}=0.1928)$. It shows that majority of the patients belong to $<6.5 \%$ group in both metformin (97.29\%) and glyburide (88.57\%) group.

\section{Antenatal complications}

Table 3: Antenatal complications.

\begin{tabular}{|llll|}
\hline $\begin{array}{l}\text { Antenatal } \\
\text { complications }\end{array}$ & $\begin{array}{l}\text { Metformin } \\
(\mathrm{n}=37)\end{array}$ & $\begin{array}{l}\text { Glyburid } \\
\mathrm{e}(\mathrm{n}=35)\end{array}$ & $\mathrm{p}$ value \\
\hline PIH & 7 & 8 & 0.681 \\
\hline $\begin{array}{l}\text { Hypoglycemia } \\
(<60 \mathrm{mg} / \mathrm{dl})\end{array}$ & 0 & 0.109 \\
\hline $\begin{array}{l}\text { Test used for calculating p value = Chi square test, } \\
\text { degree of freedom = 1 }\end{array}$ & \\
\hline $\begin{array}{l}\text { RR of developing hypoglycemia in glyburide is } 9.5 ; \\
\text { 95\% CI }\end{array}$ \\
\hline
\end{tabular}

$18.91 \%$ of patients $(n=7)$ from metformin group and $22.85 \%$ of patients $(n=8)$ from glyburide group developed pregnancy induced hypertension. No one developed hypoglycemia in metformin group and 4 (11.42\%) patients of glyburide group developed hypoglycemia. Table 3 shows that the difference between these complications are statistically not significant $(\mathrm{p}=0.681$, 0.109 ). Though $\mathrm{p}$ value is not significant for any of above mentioned antenatal complications, glyburide use is associated with 9.5 times higher risk of developing hypoglycemia in the mother during antenatal period (this is calculated using formula for relative risk);

$$
R R=\frac{a /(a+b)}{c /(c+d)}
$$

where $a=4, b=31, c=0, d=37$.

\section{Mean blood sugar levels}

Table 4 shows comparison of sugar profile of patients in both groups during treatment with OHAs was done. It shows that fasting and 2-hr post breakfast sugar level is less and statistically significant in patients receiving glyburide compared to metformin ( $\mathrm{p}=0.0001,0.0093$ ). 2-hr post lunch and 2-hr post dinner sugar level is also shown and found to be not statistically significant in between two groups.

Table 4: Mean blood sugar levels.

\begin{tabular}{|llll|}
\hline $\begin{array}{l}\text { Blood } \\
\text { glucose } \\
\text { levels } \\
(\mathrm{m} g / \mathrm{dl})\end{array}$ & $\begin{array}{l}\text { Metformin } \\
(\mathrm{n}=37)\end{array}$ & $\begin{array}{l}\text { Glyburide } \\
(\mathrm{n}=35)\end{array}$ & p value \\
\hline Fasting & $93.11 \pm 2.26$ & $88.97 \pm 3.85$ & 0.0001 \\
\hline $\begin{array}{l}\text { 2-h } \\
\text { breakfast }\end{array}$ & $121.25 \pm 4.58$ & $117.88 \pm 6.04$ & 0.0093 \\
\hline 2-h lunch & $120.96 \pm 4.28$ & $119.83 \pm 4.77$ & 0.2932 \\
\hline $\begin{array}{l}\text { 2-h } \\
\text { dinner }\end{array}$ & $119.13 \pm 4.35$ & $119.11 \pm 3.11$ & 0.9822 \\
\hline \multicolumn{4}{|l}{ Test used for calculating p value = Unpaired t test } \\
\hline
\end{tabular}

\section{Efficacy}

Table 5 compares the efficacy of both OHAs. Out of 50 patients who received metformin for treatment of GDM, $13(26 \%)$ patients failed to achieve glycemic targets and required supplemental insulin.

Table 5: Efficacy.

\begin{tabular}{|l|}
\hline $\begin{array}{l}\text { Efficacy } \\
(\mathrm{n}=50)\end{array}$ \\
\hline $\begin{array}{l}\text { Participants who } \\
\text { failed to achieve } \\
\text { glycemic targets }\end{array}$ \\
\hline $\mathrm{p}$ value $=0.006$ \\
\hline Test used for calculating p value = Fisher's exact test \\
\hline $\begin{array}{l}\text { The chi-square statistic is } 8.2817 . \text { The } \mathrm{p} \text {-value is } \\
0.004005 \text {. This result is significant at } \mathrm{p}<0.05 .\end{array}$ \\
\hline
\end{tabular}


Out of 36 patients who received glyburide for treatment of GDM, $1(2.78 \%)$ failed to achieve glycemic targets and required replacement with insulin. The difference between the efficacy of both drugs found to be statistically significant $(\mathrm{p}=0.006)$.

\section{Fetal variables}

\section{Gestational age at delivery}

The mean gestational age at delivery in weeks in metformin and glyburide group was $38.01 \pm 1.44$ weeks and $37.16 \pm 2.96$ weeks respectively; the difference being statistically not significant $(\mathrm{p}=0.1227)$. Majority of the patients delivered after 340/7 weeks in both metformin $(100 \%)$ and glyburide $(91.42 \%)$ group.

\section{Mode of delivery}

As shown in Table 6, the most common mode of delivery in patients with GDM treated with OHAs was caesarean $(n=55)$. The difference for mode of delivery in between 2 groups was found to be statistically insignificant $(\mathrm{p}=0.4879)$. One patient had hysterotomy in glyburide group for ante partum hemorrhage.

Table 6: The most common mode of delivery in patients.

\begin{tabular}{|c|c|c|}
\hline Mode of delivery & $\begin{array}{l}\text { METFORMI } \\
\mathbf{N}(\mathbf{n}=\mathbf{3 7})\end{array}$ & $\begin{array}{l}\text { GLYBURID } \\
\mathbf{E}(\mathbf{n}=\mathbf{3 5})\end{array}$ \\
\hline Normal vaginal & 7 & 9 \\
\hline operative & 30 & 26 \\
\hline \multicolumn{3}{|l|}{$\mathrm{p}$ value $=0.4879$} \\
\hline \multicolumn{3}{|c|}{$\begin{array}{l}\text { test used for calculating } \mathrm{p} \text { value }=\text { Chi square test, } \\
\text { degree of freedom }=1\end{array}$} \\
\hline
\end{tabular}

\section{Birth weight at delivery}

The mean birth weight in metformin and glyburide group was $2.98 \pm 0.649 \mathrm{~kg}$ and $2.91 \pm 0.658 \mathrm{~kg}$ respectively; the difference being statistically not significant $(\mathrm{p}=0.651)$.

Fetal growth according to Fenton's growth chart at delivery

Table 7 shows classification of fetus at the time of delivery according to Fenton's growth chart. Difference between both groups is not statistically significant ( $p$ value $=0.733$ ) was showed. Most of the fetuses are AGA in both groups; $75.67 \%$ in metformin group $(n=28)$ and $71.43 \%$ in glyburide group $(n=25)$ respectively.

Table 7 shows that though statistically insignificant; women who received glyburide for the management of gestational diabetes are at 2.1 times higher risk for developing LGA fetuses compared to metformin.

Table 7: Fetal growth according to Fenton's growth chart (111) at delivery.

\begin{tabular}{|lll|}
\hline Fetal growth & $\begin{array}{l}\text { Metformin } \\
(\mathbf{n}=37)\end{array}$ & $\begin{array}{l}\text { Glyburide } \\
(\mathbf{n}=35)\end{array}$ \\
\hline LGA & 3 & 6 \\
\hline AGA & 28 & 25 \\
\hline SGA & 6 & 4 \\
\hline p value $=0.733$ & \\
\hline $\begin{array}{l}\text { test used for calculating p value }=\text { Chi square test }-0.62, \\
\text { yates' p value }-0.733, \text { degree of freedom }=2\end{array}$ \\
\hline RR of developing LGA in glyburide is $2.1 ; 95 \% \mathrm{CI}$ \\
\hline RR of developing SGA in metformin is $1.4 ; 95 \% \mathrm{CI}$ \\
\hline
\end{tabular}

Table 8: Fetal and neonatal complications.

\begin{tabular}{|llllll|}
\hline $\begin{array}{l}\text { Complications } \\
\text { Neonatal hypoglycemia }(<40\end{array}$ & Metformin $(\mathrm{n}=37)$ & Glyburide $(\mathrm{n}=35)$ & $\mathrm{p}$ value & Test used & Relative risk \\
mg/dL) & 4 & 8 & 0.170 & Chi square & 2.11 \\
\hline Intrauterine death & 1 & 1 & 0.49 & Yates' & 1.05 \\
\hline Nursery admission & 7 & 15 & 0.027 & Chi square & 2.26 \\
\hline Shoulder dystocia & 2 & 0 & 0.498 & Yates' & 0.21 \\
\hline
\end{tabular}

\section{Fetal and neonatal complications}

Table 8 shows comparison of fetal and neonatal complications between metformin and glyburide group. Incidence of neonatal hypoglycemia, intrauterine fetal death (IUFD) and shoulder dystocia between both groups were statistically not significant $(\mathrm{p}=0.170,0.49,0.498$ respectively). Table 8 shows that $7(18.91 \%)$ fetuses of metformin group and $15(42.85 \%)$ fetuses of glyburide group required nursery admissions; the difference being statistically significant $(\mathrm{p}=0.027)$. Table 8 showed that though $p$ value is not significant for neonatal hypoglycemia, glyburide use is associated with 2.11 times higher risk of developing hypoglycemia compared to metformin. Nursery admissions were 2.26 times higher in glyburide compared to metformin.

\section{Mean blood sugar levels}

Table 9 showed comparison of sugar levels of fetuses in both groups after delivery at $1 \mathrm{hr}, 2 \mathrm{hr}$ and $4 \mathrm{hr}$. It shows that differences of mean sugar levels in the fetuses of both group were statistically insignificant $(p=0.6753$, 0.2434 and 0.6728 respectively). 
Table 9: Mean blood sugar levels.

\begin{tabular}{|c|c|c|c|}
\hline $\begin{array}{l}\text { Mean blood } \\
\text { glucose } \\
\text { levels } \\
\text { (mg/dl) }\end{array}$ & $\begin{array}{l}\text { Metformin } \\
(n=36) 1 \\
\text { IUFD }\end{array}$ & $\begin{array}{l}\text { Glyburide } \\
(n=34) 1 \\
\text { IUFD }\end{array}$ & $\begin{array}{l}\text { p } \\
\text { Value }\end{array}$ \\
\hline $\begin{array}{l}\text { Blood sugar } \\
\text { of } 1 \mathrm{hr} \text { after } \\
\text { birth }\end{array}$ & $49.52 \pm 6.64$ & $48.85 \pm 6.68$ & 0.6753 \\
\hline $\begin{array}{l}\text { Blood sugar } \\
\text { of } 2 \text { hr after } \\
\text { birth }\end{array}$ & $54.25 \pm 7.56$ & $52.11 \pm 7.65$ & 0.2434 \\
\hline $\begin{array}{l}\text { Blood sugar } \\
\text { of } 4 \mathrm{hr} \text { after } \\
\text { birth }\end{array}$ & $54 \pm 6.68$ & $53.32 \pm 6.73$ & 0.6728 \\
\hline
\end{tabular}

\section{Other findings}

Two patients from metformin group had gastrointestinal side effects and discontinued medication. Two patients from glyburide group had persistent hypoglycemia and discontinued medication. One congenital anomaly (sprengel deformity) was detected in the glyburide group.

\section{DISCUSSION}

Worldwide many studies have been performed to see the place of OHAs in the management of GDM. Recently, in January 2015 the editorial article of the British Medical Journal mentioned that more studies are needed to conclude which OHA would be a preferred alternative to Insulin in the management of GDM. ${ }^{13}$

In India only 3 studies have evaluated the role of second generation sulfonylurea glyburide in the management of GDM compared to insulin. ${ }^{14-16}$ In 2006, Anjalakshi et al compared glyburide and insulin in randomized controlled trial for the management of GDM. Out of 26 GDM women 10 received glyburide and 13 received insulin. Mean postprandial blood sugar in the glyburide group was $95.29 \pm 7.41 \mathrm{mg} / \mathrm{dl}$ and in the insulin group was $93 \pm$ $9.75 \mathrm{mg} / \mathrm{dl}(\mathrm{p}=0.54) .{ }^{14}$ Out of 10 patients treated with glyburide no one required replacement with insulin to achieve glycemic targets. They concluded that glyburide can be an effective alternative to the insulin for the management of GDM.

In 2012, Mukhopadhyay et al randomized 60 patients of GDM who were not able to achieve glycemic targets with MNT and exercise to glyburide $(n=30)$ and insulin $(n=30)$. They found that both groups had similar levels of fasting and postprandial glycemic controlwith $p$ value of 0.97 and 0.07 respectively. There was no significant difference in perinatal outcomes in between the two groups. ${ }^{15}$ Neonatal hypoglycemia and LGA were slightly higher in the infants whose mother was treated with glyburide compared to insulin.
In 2013, Tempe et al performed a randomized study with the aim of assessing efficacy of glyburide in gestational diabetes and to compare maternal and fetal outcomes of the patients of GDM treated with glyburide and insulin. ${ }^{16}$ They found no significant difference in the achievement of glycemic control between the insulin and the glyburide treated groups $(97.1 \%, 93.8 \%)$. The occurrence of maternal complications $(\mathrm{P}=0.87)$ and fetal complications $(\mathrm{P}=0.32)$ were comparable too in between two groups. 2 patients out of 32 patients of glyburide failed to achieve glycemic control with maximum dose of glyburide (20 $\mathrm{mg} / \mathrm{d}$ ) and required replacement with insulin.

No study in India has compared metformin and glyburide for the management of GDM to date. We did this study to see the scope of glyburide compared to metformin and to compare their effect on maternal, fetal and neonatal variables in Indian population.

Worldwide, only two studies have been published comparing metformin and glyburide in GDM. ${ }^{17,18}$ In 2010, Moore et al compared efficacy of metformin and glyburide in the management of GDM. They found failure rate of metformin $(34.7 \%) 2.1$ times higher than glyburide $(16.2 \%){ }^{17}$ Failure rate of glyburide in this study $(16.2 \%)$ is significantly higher than the $4 \%$ failure rate reported in the initial study by Langer et al, failure rate of metformin in this study $(34.7 \%)$ is in line with the study reported by Rowan et al in which $46.3 \%$ of patientsreceiving metformin received supplemental insulin to achieve euglycemia. ${ }^{19,20}$ Among maternal variables glycemic control of both groups were comparable. The mean birth weight of fetuses in the metformin group was smaller than the mean birth weight of fetuses in the glyburide group ( $p=0.02)$. LGA fetuses were more in glyburide group compared to metformin group with relative risk of 3 . Other findings were comparable in both groups.

In 2010, Silva JC et al compared these two drugs for the management of GDM. They found less maternal weight gain with metformin than glyburide $(\mathrm{p}=0.02)$. Other variables like efficacy or failure of drug, mean level of fasting or postprandial plasma glucose, weight of the baby, rate of LGA newborns and neonatal hypoglycemia found to be statistically insignificant between both groups. ${ }^{18}$

In our study primary objective was to assess the glycemic control during antenatal period while receiving OHAs. We found that both metformin and glyburide have achieved the targeted glycemic values but fasting and 2 hr post breakfast glucose values were found to be lower and statistically significant in glyburide group as compared to metformin. This may be explained by the well known profound hypoglycemic effect of glyburide or may be due to use of $2.5 \mathrm{mg}$ twice a day as starting dose of glyburide in treating patients with mild level of hyperglycemia diagnosed with DIPSI single 2-hr $75 \mathrm{~g}$ OGTT value. Meta-analysis in 2007, Gangji et al.(21) 
concluded that glyburide is associated with $52 \%$ increased risk of hypoglycemia compared with insulin and other secretagogues without increasing other side effects like cardiovascular events, death, or weight gain. This could be explained by glyburide's increased effect on hepatic insulin sensitivity through high affinity for the $\beta$-cell sulfonylurea receptor, accumulation of active metabolites, and general accumulation in the islet $\beta$-cell, which causes insulin release even after the medication is stopped. ${ }^{22}$

With pre-defined maximum dose of both OHAs, metformin (2.5 g/day) failed to achieve glycemic targets in $26 \%$ of patients compared to $2.77 \%$ failure rate of glyburide $(20 \mathrm{mg} / \mathrm{day})$. In our study, the failure rate of metformin was 9.39 times higher than the failure rate of glyburide when used in the management of gestational diabetes (95\% CI 1.383 to 2.361 ).

Failure rate of metformin in our study $(26 \%)$ is comparable to the failure rate found in the studies comparing metformin and insulin available till now. Meta-analysis published in 2015, Balsells et al found the average failure rate of metformin $33.8 \%$ when metformin was used for the management of GDM. This metaanalysis included six randomized trials comparing metformin and insulin. ${ }^{23}$

Failure rate of glyburide in our study $(2.77 \%)$ is also comparable to studies comparing glyburide and insulin. The meta-analysis published in 2015, Odiba et al found the average failure rate of glyburide $6.47 \%$ when glyburide was used for the management of GDM. This meta-analysis included eight randomized trials comparing glyburide and insulin in the management of gestational diabetes mellitus. ${ }^{24}$ Failure rate of glyburide in our study is quite low compared to the studies which have compared metformin and glyburide. This may be because of treating mild level of hyperglycemia when diagnosing GDM according to single $75 \mathrm{~g} 2 \mathrm{hr}$ OGTT value. This failure rate of glyburide can be explained by the range of failure rate of glyburide in studies comparing glyburide and insulin worldwide; which is 2.43 to $20.83 \%$ (average $6.64 \%){ }^{24}$ Three Indian studies which have compared glyburide with insulin shows failure rate ranging from 0 to $6.25 \%$ (average $2.8 \%$ ) and this is comparable with our study findings.

Remaining maternal variables like age, number of previous pregnancies, family history, past history, $75 \mathrm{gm}$ 2-hr OGTT (mg/dl), BMI at diagnosis of GDM $\left(\mathrm{kg} / \mathrm{m}^{2}\right)$, $\mathrm{A} 1 \mathrm{C}$ at diagnosis of GDM, gestational age at diagnosis of GDM, gestational age at the time of inclusion in study and weeks of treatment with oral hypoglycemic agents were found to be statistically insignificant during comparison.

In our study, nursery admissions for fetuses were higher $(42.85 \%)$ and statistically significant $(\mathrm{p}=0.027)(\mathrm{RR}=$ 2.26) in the glyburide group compared to metformin.
Recently in May 2015, Camelo et al. compared glyburide and insulin for fetal variables. They concluded that a fetus of the mother treated with glyburide is at 2.97 times higher risk of admission to nursery compared to fetuses of the mother treated with insulin. So, this finding is justified. ${ }^{25}$

Other adverse perinatal outcomes which were higher in glyburide group in our study were fetuses with LGA and neonatal hypoglycemia. Both findings were not statistically significant but relative risk of developing neonatal hypoglycemia $(<40 \mathrm{mg} / \mathrm{dl})$ is 2.11 times more when mother is exposed to glyburide compared with metformin and relative risk of developing LGA fetuses is also 2.11 times more with glyburide compared to metformin. Two recently published articles are in support of these findings. Out of two, one is meta-analysis published by Balsells et al. who compared OHAs with insulin and with each other and in another concluded that glyburide treatment for gestational diabetes is associated with higher macrosomia and neonatal hypoglycemia. In another article published in 2015; Odiba et al. compared glyburide and insulin for perinatal outcomes and found that treatment of gestational diabetes with glyburide is associated with 1.40 times increased risk of neonatal hypoglycemia and 1.41 times increased risk of having LGA. $^{23,25}$

The study was started with null hypothesis. According to that it was presumed that metformin and glyburide are equally effective in achieving glycemic targets without affecting maternal, fetal or neonatal outcomes. Study results prove that glyburide is more effective compared to metformin in the management of GDM but at a cost of increased risk of hypoglycemia in mother during antenatal period and higher risk of LGA, neonatal hypoglycemia, nursery admissions in fetuses.

Findings of this study question the widespread use of glyburide as first line management modality in the management of GDM and as an alternative to insulin as advised by many groups. ${ }^{26,27}$

Further studies are required to prove Glyburide's role and see whether it can be added to metformin in place of insulin when metformin fails to achieve glycemic targets. Adverse perinatal outcomes in glyburide group should raise question of placental transfer of the glyburide and studies should be done to see cord blood levels of glyburide. Role of other second generation sulfonylureas may be evaluated in place of glyburide for the management of gestational diabetes.

\section{CONCLUSION}

While studying metformin and glyburide in the management of GDM for short term maternal, fetal and neonatal variables over a period of one year; we found that failure rate of metformin is higher compared to glyburide in achieving glycemic targets. However, 
glyburide use is associated with higher risk of maternal hypoglycemia, neonatal hypoglycemia, LGA fetuses and higher rate of nursery admissions compared to metformin. Thus, metformin should be considered as an alternative to insulin for the management of GDM. Glyburide should be second line management when patient is not able to achieve glycemic targets with metformin or when patient is not able to tolerate metformin until its perinatal safety is proved or the availability of long term studies. Strict glucose monitoring is required to prevent glyburide induced hypoglycemia during treatment. From our study we think that to avoid glyburide induced maternal hypoglycemia, glyburide could have been started with $1.25 \mathrm{mg}$ twice a day dose while treating mild level of hyperglycemia.

\section{Funding: No funding sources}

Conflict of interest: None declared

Ethical approval: The study was approved by the Institutional Ethics Committee

\section{REFERENCES}

1. World Health Organization. Dept. of Noncommunicable Disease Surveillance, Definition, diagnosis and classification of diabetes mellitus and its complications. Report of a WHO consultation. Part 1: diagnosis and classification of diabetes mellitus. 1999. Available from: http://www.who.int/iris/handle/10665/66040.

2. Seshiah V, Das AK, Balaji V, Joshi SR, Parikh MN, Gupta S. Diabetes in Pregnancy study group. gestational diabetes mellitus-guidelines. J Assoc Physicians India. 2006;54:622-8.

3. Metzger BE, Coustan DR. Summary and recommendations of the fourth International WorkshopConference on gestational diabetes mellitus. The Organizing Committee. Diabetes Care. 1998;2:161-7.

4. Seshiah V, Balaji V, Balaji MS. Pregnancy and diabetes scenario around the world: India. Int J Gynaecol Obstet. 2009;104(1):35-8.

5. Seshiah V, Balaji V, Balaji MS, Sanjeevi CB, Green A. Gestational diabetes mellitus in India. J Assoc Physic India. 2004;52:707-11.

6. Seshiah V, Banerjee S, Balaji V, Muruganathan A, Das AK. Consensus Evidence-based guidelines for management of gestational diabetes mellitus in India. Journal Asso Physicians India. 2014;62.

7. Langer O, Yogev Y, Most O, Xenakis EM. Gestational diabetes: the consequences of not treating. Am J Obstet Gynecol. 2005;192(4):989-97.

8. Crowther CA, Hiller JE, Moss JR, McPhee AJ, Jeffries WS, Robinson JS. Effect of treatment of Gestational diabetes mellitus on pregnancy outcomes. Australian Carbohydrate intolerance study in pregnant women (ACHOIS) trial group. New England J Med. 2005;352(24):2477-86.

9. Langer O. Oral antidiabetic drugs in pregnancy. Diabetes Spectrum. 2007;20(2):101-5.

10. Alwan N, Tuffnell DJ, West J. Treatments for gestational diabetes. Cochrane Database Syst Rev. 2009;3:CD003395.
11. Camelo CW, Boggess K, Sturmer T, Brookhart MA, Benjamin DKJ, Jonsson FM. Trends in glyburide compared with insulin use for gestational diabetes treatment in the United States: 2000-2011. Obstet Gynecol. 2014;123:1177-84.

12. Heilmaier C, Thielscher C, Ziller M, Altmann V, Kostev K. Use of antidiabetic agents in the treatment of gestational diabetes mellitus in Germany, 2008-2012. J Obstet Gynaecol Res. 2014;40:1592-7.

13. Sacks DA. Which oral hypoglycaemic for gestational diabetes? BMJ. 2015;350:177.

14. Anjalakshi C, Balaji V, Balaji MS, Seshiah V. A prospective study comparing insulin and glibenclamide in gestational diabetes mellitus in Asian Indian women. Diabetes Res Clin Pract. 2007;76:474-5.

15. Mukhopadhyay P, Bag TS, Kyal A, Saha DP, Khalid N. Oral hypoglycemic glibenclamide: can it be a substitute to insulin in the management of gestational diabetes mellitus? A comparative study. JSAFOG. 2012;4:28-31.

16. Tempe A, Mayanglambam RD. Glyburide as treatment option for gestational diabetes mellitus. J Obstet Gynaecol Res. 2013;39:1147-52.

17. Moore LE, Clokey D, Rappaport VJ, Curet LB. Metformin compared with glyburide in gestational diabetes: a randomized controlled trial. Obstet Gynecol. 2010;115:55-9.

18. Silva JC, Fachin DR, Coral ML, Bertini AM. Perinatal impact of the use of metformin and glyburide for the treatment of gestational diabetes mellitus. J Perinat Med. 2012;40:225-8.

19. 19. Langer O, Conway DL, Berkus MD, Xenakis EM, Gonzales O. A comparison of glyburide and insulin in women with gestational diabetes mellitus. $\mathrm{N}$ Engl $\mathrm{J}$ Med. 2000;343:1134-8.

20. Rowan JA, Hague WM, Gao W, Battin MR, Moore MP. Metformin versus insulin for the treatment of gestational diabetes. N Engl J Med. 2008;358(19):200315.

21. Gangji AS, Cukierman T, Gerstein HC, Goldsmith $\mathrm{CH}$, Clase CM. A systematic review and meta-analysis of hypoglycemia and cardiovascular events: a comparison of glyburide with other secretagogues and with insulin. Diabetes Care. 2007;30(2):389-94.

22. Szoke E, Gosmanov NR, Sinkin JC, Nihalani A, Fender $\mathrm{AB}$, Cryer PE, et al. Effects of glimepiride and glyburide on glucose counterregulation and recovery from hypoglycemia. Metabolism. 2006;55(1):78-83.

23. Balsells M, Garcia-Patterson A, Sola I, Roque M, Gich I, Corcoy R. Glibenclamide, metformin, and insulin for the treatment of gestational diabetes: a systematic review and meta-analysis. BMJ. 2015;350:102.

24. Odiba JO, Mabhala MA. The Effectiveness of Glyburide Compared to Insulin in the Management of Gestational Diabetes Mellitus: A Systematic Review. Journal Diabetes Mellitus. 2015(5):58-66.

25. Camelo Castillo W, Boggess K, Sturmer T, Brookhart MA, Benjamin DK, Jr., Jonsson Funk M. Association of Adverse Pregnancy Outcomes With Glyburide vs Insulin in Women With Gestational Diabetes. JAMA Pediatr. 2015;169(5):452-8.

26. Diabetes in pregnancy: management from preconception to the postnatal period. 2015. Available from: nice.org.uk/guidance/ng3. 
27. Committee on Practice Bulletins Obstetrics. Practice Bulletin No. 137: gestational diabetes. Obstet Gynecol. 2013;122(2 Pt 1):406-16.
Cite this article as: Pujara P, Singh V, Murmu S, Kumari S, Prajapati D. A comparative study of metformin and glyburide in gestational diabetes mellitus.Int J Reprod Contracept Obstet Gynecol 2017;6:1493-502. 